\title{
Effects of Circuit Training Exercise on Trunk Flexibility and Muscular Endurance of Female Secondary School Teachers in Anambra State
}

\author{
Dr. Ujuagu Nonye Ann and Dr. Uzor Theresa Nkiru \\ Department of Human Kinetics and Health Education, Nnamdi Azikiwe University, Awka
}

\begin{abstract}
Technological advancement and socio-economic pressure has deprived many women the time and resources to exercise and to engage in physical activities which affect their physical fitness level their physical fitness level should come up to standard that will help them to execute their duties well. Circuit training exercise which is an important aspect of this study is aimed at improving this standard. This study was designed to determine the effect of circuit training exercise programme on the selected physical fitness variables of female secondary school teachers in Anambra State. The study was guided by two research questions and two hypotheses. Randomized pretest, posttest control group design were adopted for the study and the population consisted of all the female secondary school teachers in Anambra State. The sample consisted of 60 female teachers from 6 secondary schools in Otuocha educational zone. The schools were selected with purposive sampling technique while the 60 female teachers were selected using simple random sampling technique. The instruments used for data collection are as follows - measuring tape, stop watch and gym mats. Eight weeks exercise programme was adopted for the training. Data collected were analyzed using descriptive statistics of mean and mean difference for answering the research questions. The null hypotheses were tested using Analysis of Covariance (ANCOVA) at 0.05 level of significance. The result of the study showed that experimental group recorded high mean difference in trunk flexibility and muscular endurance. There were also significant difference between the mean muscular endurance of the experimental and control group $(\mathbf{P}<0.05)$. There was no significant difference between trunk flexibility. The researcher therefore concluded that eight weeks circuit training exercise programme had an effect on the variables used in the study and recommends that exercise programmes should be introduced in our schools and be seriously upheld by every teacher in the state and from time to time, exercise programmes of this kind should be sponsored by governments and nongovernmental organizations (NGOs) to meet up with the standard of teachers required in this era.
\end{abstract}

\section{INTRODUCTION}

Cardiorespiratory fitness and muscular strength seem to provide unique and important benefits to the prevention and treatment of cardiovascular disease and mortality in addition to several other health and fitness. The degree of physical fitness depends upon the individual's state of health, constitution and level of activity, if exerted. Optimal fitness is not possible without regular physical activity. Thus, a fit person has the strength, flexibility, endurance, social and emotional adjustments appropriate for his or her age and sex to engage in daily physical activities without experiencing undue fatigue (Marc, 2011). A fit individual is one who enjoys a quality of health which enables him to live most and serve best. Regular physical activity is one of the most important things one can do for health, it can help lower the risk of heart diseases and other hypokinetics diseases (Medline plus, 2015). From a survey report of Ogu, Agbanusi and Umeasiegbu (2007), regular exercise has been shown to exert many positive effects on health while many common chronic diseases are consequences of inactivity and sedentary behaviour. Physical fitness does not apply to athletes alone. There is need for physical fitness for non-athletes, men and women, youngsters and the aged, rich and the poor because it contributes to good health and youth's growth and development (Sharkey, 2012).

Normal function of all parts of the body contributes not only to the efficiency and the ability to do a full day's work without fatigue, courage and enthusiasm for life. Barker (2010) stated that regular physical activity and good fitness not only help prevent illness and disease but also promote quality of life and wellness. He further explained that a person who can resist fatigue, muscle soreness, back problems and other symptoms associated with poor health-related fitness is capable of working productively and having energy left over at the end of the day. Stephens (2014) added that physical fitness is the basis of all activities in our society. If our bodies grow soft and inactive; if one fail to encourage physical development and prowess, we will undermine the capacity for work, and for the use of those skills vital to an expanding life.

Keywords:- Circuit Training, Exercise, Trunk Flexibility, Muscular Endurance, Fitness. 
Generally, human beings can only perform work when they are physically fit . They are more likely to have an ideal weight, feel better about themselves. With increased automation, keeping fit has become a universal problem. Today, many people are worried about the general state of their health and appearance especially women who wants to look beautiful and physically fit all the time.

Physical fitness is categorized into two aspects, healthrelated physical fitness and skill or performance related physical fitness. The President's Council on Physical Fitness and Sports (2011) defined health-related physical fitness as the ability to carry out daily tasks with vigor, without undue fatigue and with ample energy to enjoy leisure-time pursuits and to handle effectively unforeseen injuries. Its components include muscular strength, muscular endurance, cardiorespiratory endurance, flexibility and body composition. They also stated that skill-related physical fitness include those qualities or functions that provide the individual with what is necessary to participate in sports with greater skill. Under skill related physical fitness we have speed, power, balance, agility, reaction time and coordination. An important dimension of the physical fitness components that was used in this work is health-related physical fitness which includes muscular endurance and flexibility.

Quinn (2014) defines muscular endurance as the ability of a muscle or group of muscles to sustain repeated contractions against a resistance for an extended period of time. Muscular endurance is closely related to muscular strength. An individual who is strong will be more resistant to fatigue, because relatively less effort will be required to produce repeated muscular contractions. Muscular endurance is very important for people playing any sort of sports, or who are involved in any sort of physical activity that lasts for quite a while. Muscular endurance as one of the variables is measured with a bent knee sit up which are used to test the local endurance of the abdominal muscles and also depends to some degree on the muscle strength.

Wise Greek (2014) defines flexibility as the ability of a joint to move through its full range of motion. They further stated that flexibility which means attaining a full range of motion is important because it helps reduce stress on muscles as they perform various tasks, thereby reducing injury rates. Most activities people engage in require relatively "normal" amounts of flexibility. Increased flexibility may increase one's performance through improved balance and reaction time. The trunk flexibility at the lumbosacral joint is measured with a sit-and-reach test which is an excellent measure of trunk flexibility. It is usually selected because of its feasibility, reliability, logical validity and reported criterion-related validity (More 2013). The advances that are seen in technology have simplified many physically demanding tasks which women carry out in their various homes. The problem which has been created by the advances in technology especially for women is that the technology products have usurped many of those physically demanding tasks which create the opportunity for women to exercise themselves thus limiting those opportunities through which women keep physically fit. Besides more women are taking up white collar jobs which requires them to make more use of their intellectual energy and limited use of physical energy. The fact is that more women are taking up sedentary lifestyles which are closely associated with physical inactivity. The result of this is that more women run the risk of being affected by sicknesses that are associated with limited physical activity and exercise such as heart attacks, high blood pressure, diabetes etc.

\section{Research Hypothesis}

The following null hypotheses were generated:

- There is no significant difference in the mean trunk flexibility of female secondary school teachers who were trained with circuit training exercise programme (CTEP) and those not trained with CTEP.

- There is no significant difference in the mean muscular endurance of female secondary school teachers who were trained with circuit training exercise programme (CTEP) and those not trained with CTEP.

\section{METHODOLOGY}

\section{A. Research Design}

The research design used for this study was the randomized pretest - posttest control group design, utilizing a $2 \times 2$ factorial design, where two groups of subjects are involved, the control group and experimental group. This design is appropriate for this study because it is a true experimental research design.

\section{B. Population}

The population of the study consists of all the female secondary school teachers in Anambra State. Whose populations are about 5,975(Department of Planning, Research and Statistics Post Primary School Service Commission Headquarters Awka 2019).

\section{Instrumentation:}

The instrument used to collect data for this study included:

Measuring Tape: The non-elastic type measuring $152 \mathrm{~mm}$ was used to mark off the $400 \mathrm{~m}$ track into $50 \mathrm{~m}$ bits.

Step Bench: A sturdy - step bench $40 \mathrm{~cm}$ high was used to aid accurate measurement of the sit and reach test, and for the step up circuit of the training programme.

Gym Mats: The sit and reach test and sit-up were used to perform on gym mats. Also all the circuits that require lying down were done on gym mats. 


\section{Exercise Protocol}

The training session starts with warm -up activities. The circuit training lasted 30 minutes and 4 minutes for cool down stretch. The duration of the circuit training was increase to 40 minutes before the end of the programme, 6 minutes for warm- up stretches or exercises, and 4 minutes for cool down stretch.

All participants in the experimental group (30 female teachers) were divided into 5 groups (6 participants in each group). The groups performed the circuit strength training exercises at the different stations. Each group of participants exercised at each station and will have 1 minute rest between stations. The participants moves from one station to the other in a clockwise direction as soon as the time allotted to each station is over, they were required to go through the 5 stations of the circuit three times with 4 minutes rest between sets. Circuit training exercises for the sections are as follows:

\section{Station 1}

Bench Stepping

Action - The participants stepped up and down a bench $38.9 \mathrm{~cm}$ high. They performed one set using the same Leg each time, second set using the other leg and alternates legs on each step - up cycle.

\section{$>$ Station 2}

Sit-up

Action: The participant lied flat on the floor with feet behind wall bars and knees slightly bent, palms clasped behind the head, repeat sit - up with trunk twisting.

\section{Station 3}

Modified Push - Up

Action: The participants maintained their body as straight as possible in a raiment position with the arms and balls of the toes supporting the body. The participants flexed the elbows, lowering the body until it almost touches the floor, than raises the back up to the starting position.

\section{Station 4}

Abdominal Crunch

Action: The participant's heads and shoulders are off the floor, arms are crossed on the chest, and knees slightly bent. The participant curls up to at least $90^{\circ}$ and return to the original position.
Station 5

Rowing, Torso

Action: The participants' partner applies enough pressure on the elbows to gradually force the arms forward (horizontal flexion) while the participants tries to resist the pressure. Next, they will reverse the action horizontally forcing the arms backwards as the partner applies sufficient pressure to create resistance.

Circuit Training Exercise for Week 2, 4, 6 \&

\section{Station 1}

\section{High knee Jogging}

Action: The participants go on a high knee jogging on the spot for the duration of station.

\section{Station 2}

\section{Rope Skipping}

Action: The participants did rope skipping with one leg and later with alternate legs.

\section{Station 3}

Crunch (curl-up)

Action: Prone lying, palms clasped behind the head, with knees bent, curl up until should blade leave floor, then roll-up to the starting position.

\section{Section 4 \\ Modified Push-up}

Action: With the knee bent at right angles and the hands on the floor, the participants lowered her body to the floor until the chest touched the floor and then pushed back to the starting position.

\section{Station 5}

Burpee

Action: The participants stands with their hands at their sides, she bent her knees and places her hand on the floor in front of foot, she trusted her legs back to a full extended position, a front learning rest position, return to erect position. This process was repeated until the time allotted for the exercise lapsed.

\section{E. Method of Data Analysis}

Descriptive and inferential statistical procedures were used to analyze the data. The mean scores and mean difference for each of the variables pre and posttest was computed and used in answering research questions, and also the null hypotheses was tested at 0.05 level of significance using Analysis of Covariance (ANCOVA) to determine if there was any significance difference in performance of female teachers who were trained and those not trained. 


\section{RESULTS}

Data in figure1 was used to answer research question one;

\begin{tabular}{|c|c|c|c|c|c|}
\hline \multirow{2}{*}{ Group } & \multicolumn{2}{|c|}{ Pre-test } & \multicolumn{2}{c|}{ Post-test } & $\begin{array}{c}\text { Mean } \\
\text { Difference }\end{array}$ \\
\cline { 2 - 6 } & $\mathbf{N}$ & Mean & N & Mean & \\
\hline Experimental & 30 & 13.10 & 30 & 13.45 & 0.35 \\
\hline Control & 30 & 12.96 & 30 & 13.03 & 0.07 \\
\hline
\end{tabular}

Table1:- Mean Difference Scores on the Trunk Flexibility of

Female Secondary School Teachers Trained with Circuit Training Exercise Programme (CTEP) and those not Trained.

The data in table 6 shows that the experimental group had pretest and posttest trunk flexibility of 13.10 and 13.45 while that of the control group were 12.96 and 13.03. This indicates a mean difference of 0.35 and 0.07 for experimental and control groups respectively. The mean difference in trunk flexibility from pretest to posttest was higher for experimental group than control group.

Data in figure 2 are used to answer research question 2.

What is the difference in the pretest and posttest mean muscular endurance of female secondary school teachers
ISSN No:-2456-2165

trained with circuit training exercise programme (CTEP) and those not trained with circuit training exercise programme?

\begin{tabular}{|c|c|c|c|c|c|}
\hline \multirow{2}{*}{ Groups } & \multicolumn{2}{|c|}{ Pre-test } & \multicolumn{2}{c|}{ Post-test } & Mean Difference \\
\cline { 2 - 6 } & N & Mean & N & Mean & \\
\hline Experimental & 30 & 9.00 & 30 & 11.83 & 2.83 \\
\hline Control & 30 & 8.80 & 30 & 8.83 & 0.03 \\
\hline
\end{tabular}

Table 2:- Mean Difference Scores on the Muscular Endurance of Female Secondary School Teachers Trained with Circuit Training Exercise Programme (CTEP) and those not trained.

The data in table 7 shows that the experimental group had pretest and posttest mean muscular endurance of 9.00 and 11.83 while that of the control group were 8.80 and 8.83 . This indicates a mean difference of 2.83 and 0.03 for experimental and control groups respectively. The mean difference in muscular endurance from pretest to posttest was higher for experimental group compared to the control group.

Hypothesis 1: There is no significant difference in the mean trunk flexibility of female secondary school teachers who were trained with circuit training exercise programme (CTEP) and those not trained with (CTEP).

\begin{tabular}{|c|c|c|c|c|c|}
\hline Source of variation & Type III sum of square & Df mean Square & $\mathbf{F}$ & $\mathbf{P}$ & Partial Eta squared \\
\hline Corrected Model & $276.810^{\mathrm{a}}$ & $\begin{array}{ll}2 & 138.40 \\
\end{array}$ & 15.781 & .000 & .356 \\
\hline Intercept & 191.649 & 1191.649 & 21.852 & .001 & .277 \\
\hline PRERHR & 257.657 & $1 \quad 257.657$ & 257.657 & .000 & .340 \\
\hline GRP & 21.590 & 121.590 & 2.462 & .122 & .041 \\
\hline Error & 499.899 & $28 \quad .770$ & & & \\
\hline Total & 9999.710 & 60 & & & \\
\hline Corrected Total & 776.710 & 59 & & & \\
\hline
\end{tabular}

Table 3:- Summary of ANOVA Analysis on the Difference in the Mean Score of Muscular Endurance of the Experimental and Control Groups.

a. $\mathrm{R}$-squared $=.356($ Adjusted $\mathrm{R}$ squared $=.334)$

Table 13 reveals that there was no significant difference between the mean trunk flexibility of the experimental and control groups, $\mathrm{F}(1,57)=2: 462, \mathrm{P}(0.122)>0.05, \mathrm{y}_{\mathrm{P}}^{2}=.041$. Therefore, the null hypothesis was not rejected. This shows that circuit training exercise programme had no effect on the trunk flexibility of female secondary school teachers.
Hypothesis 2: There is no significant difference in the mean muscular endurance of female secondary school teachers who were trained with circuit training exercise programme (CTEP) and those not trained with (CTEP).

\begin{tabular}{|c|c|c|c|c|c|}
\hline Source of variation & Type III sum of square & Df mean Square & $\mathbf{F}$ & $\mathbf{P}$ & Partial Eta squared \\
\hline Corrected Model & $11809.419^{\mathrm{a}}$ & $2 \quad 5904.710$ & 204.051 & .000 & .877 \\
\hline Intercept & 1918.556 & 1918.556 & 66.300 & .001 & .538 \\
\hline PREMUSEND & 27.009 & 27.009 & .933 & .338 & .016 \\
\hline GRP & 11722.768 & 11722.768 & 405.107 & .000 & .877 \\
\hline Error & 1649.437 & 28.937 & & & \\
\hline Total & 42976.000 & 60 & & & \\
\hline Corrected Total & 13458.856 & 59 & & & \\
\hline
\end{tabular}

Table 14:- Summary of ANCOVA Analysis on the Difference in the Mean Score of Muscular Endurance of the Experimental and Control Group.

a. $\mathrm{R}$-squared $=.877$ (Adjusted R squared $=.873$ ) 
Table 14 reveals that there is a significant difference between the mean score of muscular endurance of the experimental and control, $\mathrm{F}(1,57)=405.107, \mathrm{P}<0.05, \mathrm{\eta}_{\mathrm{P}}^{2}=$ .877. Therefore, the null hypothesis was rejected. This shows that circuit training exercise programme had an effect on the muscular endurance of the trained group of female secondary school teachers.

\section{DISCUSSION}

Trunk flexibility of female teachers trained with CTEP and those not trained.

When the difference between experimental and control group training exercise programme on trunk flexibility was analyzed to help find the effects, the result of the study showed that the experimental group had higher mean $(\bar{x}=$ 13.45) than the control group with $(\bar{x}=12.96)$. Analysis of covariance carried out showed that there is no significant difference between the mean score of trunk flexibility of the experimental and control groups eight weeks of (CTEP). This may be due to some difficulties encountered during the training exercise. The result of the study is related to what Karen, (2011) opined, that flexibility is highly adaptable, which means it can be increased and decreased with inactivity. With the data analyzed according to muscular endurance, the result of the study showed that the experimental group recorded higher mean score than the control group after eight weeks of circuit training exercise programme. However the analysis of convariance carried out showed that there was a significant difference between the mean score of muscular endurance of the experimental and control groups after eight weeks of (CTEP), which indicates that the trained participant performed better than the untrained. Moreover the finding agrees with the findings of Marx, Rataniess, Nindl, Gotshalk, Volek, Dohietal (2011) on circuit training, the training programme had a greater effect on muscular endurance. The result of their findings also showed that when the untrained group where given a single-set circuit exercise their performance increased. The result of the study is also supported by the findings of Astrand (2009) who affirms that the improvement of muscular endurance is a result of more abundant supply of blood to the muscles performing a particular work. Hyman (2010) corroborated this view when he asserted that there was a significant improvement in muscle bloodflow as a result of training regimen of participants.

\section{CONCLUSIONS}

The following conclusions were drawn based on the findings of the study:

1. Muscular endurance and trunk flexibility of the female secondary schools teachers who were trained showed a higher mean difference than the untrained also (CTEP) had an effect on them.
2. There were no statistical difference between the mean score of trunk flexibility of the experimental and control groups after eight weeks of CTEP.

3. Statistically, there were significant differences between the mean score of muscular endurance of the experimental and control groups after eight weeks of CTEP.

\section{RECOMMENDATION}

Based on the findings of this study the researcher recommends that exercise programmes should be introduced in our schools and be seriously upheld by every teacher in the state and from time to time, exercise programmes of this kind should be sponsored by governments and non-governmental organizations (NGOs) to meet up with the standard of teachers required in this era.

\section{REFERENCES}

[1]. Astrand (2009). Textbook of work physiology New York, MC Graw- Hiu.

[2]. Bake, L.D (2010). Effects of aerobic exercise on middle cognitive impairment Archives of Neurology 67(1): 7179.

[3]. Department of Planning, Research and Statistics Post Primary School Service Commission Headquarters Awka 2019.

[4]. Hyman, .I. (2010). Human cardiovascular adjustment to exercise and thermal stress. Physiol. Rev 54: 75-159.

[5]. Karen, M. (2011) M.A. Candidacy kinesiology/Exercise physiology Research Quarterly. 29: 205-210.

[6]. Marc, S. A (2011). Practical fitness advise for everyone. Morb mortal wklykep 42. 66-672.

[7]. Max, J. O.; Ratamess, N. A.; Nindi, B. C.; Gotshalk, L. A.; Volek, J. S., Dohik; Bush, J. A; \& Gomez, A. L; (2011). Low volume circuit versus high - volume. Periodzed resistance training in women. Medicine \& Science Sports \& Exercise, 33(4), 6.35-643.

[8]. Medline plus (2015). Exercise and physical fitness: www.nlm.nih.gov>Home> Healthtopics

[9]. More .J. (2013).Physiology of exercise $6^{\text {th }}$ edition. St Loius the e. v. Mosby company.

[10]. Ogu, O.C., Agbanusi, E.C. \&UmesiegbuG.p (2007). Survey of leisure Time Physical Activity of Nnamdi Azikiwe University Students. Journal of ICHPER S.D. African Region 2(2):21-27.

[11]. Sharkey, B.J (2012).Fitness \& Health campaign, k. Human. Kinetics, ISBN 07036039716

[12]. The president's council on physical fitness and sports (2011). Definition of health related fitness. www. My fitness road. Can.ND.

[13]. Qunn, E. (2014).Sports medicine about. Com. Exercise science Basics .ND.

[14]. WWW. Wisegeek. Ora. (2014). what is cardiovascular fitness. Www. wisegeek. Org. 